\title{
Impact of climate change in urban meteorology and energy demand
}

\author{
San José R. ${ }^{1}$, Pérez J.L. ${ }^{1}$, González, R.M ${ }^{3}$., Pecci J. ${ }^{2}$, Garzón A. ${ }^{2}$, Palacios M. ${ }^{2}$ and Pérez L. ${ }^{1}$ \\ ${ }^{1}$ Environmental Software and Modelling Group \\ Computer Science School, Technical University of Madrid (UPM) \\ Campus deMontegancedo. Boadilla del Monte. 28660. Madrid. Spain \\ Phone/Fax number+34-91-336 74 65, e-mail: roberto@fi.upm.es \\ ${ }^{2}$ Indra S.A \\ C/ Mar Egeo, 4, Pol. Industrial 1, 28830 San Fernando de Henares, Madrid (Spain) \\ ${ }^{3}$ Department of Geophysics and Meteorology, Faculty of Physics, Complutense University of Madrid (UCM), Ciudad \\ Universitaria, 28040 Madrid
}

\begin{abstract}
Climate change large impacts on urban scales. Local meteorology, air pollution and energy demand of the buildings are areas affected directly by the climate change. To quantify the future impacts, this research make a dynamical downscaling from global climate data to urban high spatial resolution to produce weather data and this information can be used in the energy demand models as EnergyPlus. Dynamical downscaling process has been implemented with the mesoscale model WRF-Chem (NOAA, US) up to $1 \mathrm{~km}$ and MICROSYSCFD (UPM, ES) model from very high spatial resolution. A medium office building was simulated using meteorological downscaled datasets for Madrid. In this contribution we have used global climate models RCP scenarios to produce climate scenarios at urban scale with $10 \mathrm{~m}$ spatial resolution. We will show the results and the impacts for future (2030, 2050 and 2100) RCP IPCC 4.5 and 8.5 climate scenarios compare with the 2011 control year information for climate and buildings energy demand over Madrid, Milan and London (KensingtonChelsea area).
\end{abstract}

\section{Key words}

Climate, urban, energy, WRF/Chem, EnergyPlus.

\section{Introduction}

Adverse effects of climate change are particularly relevant for urban areas where more intense and frequent heat waves are expected. If we are capable to produce detailed information of the about these impacts to understand the interaction of climate change with urban areas making possible implementing the best mitigation and adaptation strategies. Climate change will have a large impact on building energy use for heating and cooling because of the change in outdoor conditions [1]. Energy consumption levels for cooling and heating are expected to increase and decrease, respectively, as a result of global warming [2]. A detailed analysis of heating and cooling energy use in the future is needed to better understand the impact of climate change on building energy consumption because the local conditions and influence of the buildings in the environment can be very important in same locations. A detailed prediction of the future climate is the first requirement for an energy analysis of buildings. We will use the EnergyPlus [3] model to analyse the impact of climate change on the buildings.

Future climate scenarios have been developed with Global Climate Models (GCMs) [4] but with a coarse resolution, about $1^{\circ}$, so they cannot represent the local phenomena. It is necessary to apply dynamical downscaling techniques where, outputs from a GCM are used as input and boundary conditions [5] for a Regional Climate Model (RCM) up to 1 kilometre of spatial resolution. In case or the urban areas with building blocks, [6] this spatial resolution is not enough and we need to make Computational Fluid Dynamics (CFD) simulations with meters of spatial resolution. The atmospheric flow and microclimate are influenced by the urban features, so urban modelling systems should consider the influence of buildings.

This work is part of the EU FP-7 DECUMANUS project. The objective of this project is the development and consolidation of a set of services to support sustainable choices that enable city managers to deploy geospatial products in the development and implementation of strategies for energy efficiency and climate change, in meeting the many challenges of sustainable urban planning and development [7], [8], [9], [10]. The DECUMANUS services provide information to end users (city managers).

\section{Methodology}

In this research, we dynamically downscaled the years 2011, 2030, 2050 and 2100 under two IPCC RCP scenarios, 4.5 and 8.5. All simulations have been run for full year time period. RCP 4.5: Stabilization without overshoot pathway to $4.5 \mathrm{~W} / \mathrm{m} 2$ at stabilization after 2100 by employment of a range of technologies and strategies for reducing greenhouse gas emissions. RCP 8.5: Rising radiative forcing pathway leading to $8.5 \mathrm{~W} / \mathrm{m} 2$ in 2100 [11], [12], [13]. The 8.5 pathway arises from little effort to 
reduce emissions and represents a failure to curb warming by 2100 .

In our case we have used global data from six hours outputs coming from the Community Earth System Model (CESM) version 1.0. (RCP 4.5 and RCP 8.5 scenarios) which are published in the Earth System Grid web. The Weather Research Forecasting and Chemical (WRF/Chem) model is used as RCM [14], [15], [16] to dynamical downscaling from $1^{\circ}$ spatial resolution (global scale) to $1 \mathrm{~km}$ of spatial resolution (local scale). We have implemented meteorological and air quality simulations with WRF/Chem, covering all Europe with $25 \mathrm{~km}$ spatial resolution and 33 vertical levels up to $50 \mathrm{hPa}$. Next step is nesting two domains with 5 and $1 \mathrm{~km}$ of spatial resolution over Madrid, Milan and London, using the WRF-Chem Europe scale model outputs as boundary . To take into account the buildings we have used the MICROSYS CFD system. MICROSYS is based onthe CFD MIMO model [17], [18], [19] and [20]. Fig. 1 shows the workflow of the simulation framework from the global climate model to the buildings city level.

There are several studies of the impact of future climate projections on buildings energy demand [21], but they don't use very high spatial resolution hourly climate information, like datasets generated in this paper with a dynamical downscaling technique. This paper presents the results of an office building simulation study, with the purpose of examining the impact of climate change on annual building energy consumption over Madrid.

The energy study has been implemented with the EnergyPlus model, EnergyPlus is a well known and highly validated model that is the industry standard. EnergyPlus has been validated in numerous tests from ASHRAE. EnergyPlus is a highly detailed building thermal load simulation program that relies on detailed user inputs. EnergyPlus calculates heating and cooling loads, and energy consumption, using sophisticated calculations of heat gain and heat loss including transient heat conduction though building envelop elements. It also accounts for heat and mass transfer that impact sensible and latent thermal loads due to ventilation and infiltration. Additionally, the model has detailed calculations of heat transfer to or from the ground and comprehensive models of solar gain through the fenestration and opaque envelop components.

Building features needed for implementation in EnergyPlus, were taking from the ASHRAE 90.1 Prototype Building Modeling Specifications. We have selected a medium office building as prototype building because in 2015, there were roughly 30000 office buildings in Madrid, which is an important number. The medium office building has three floors with a total area of $5000 \mathrm{~m} 2$ and 268 people working in the office. Outdoor ventilation air requirements and schedules are defined following the ASHRAE 90.1 Prototype Building Modeling Specifications [22].

The following meteorological downscaled datasets was generated to the EnergyPlus meteorological input file format: Dry bulb temperature, dew point temperature, relative humidity, atmospheric pressure, horizontal infrared radiation intensity, wind direction, wind speed, total sky cover, snow depth and liquid precipitable depth.

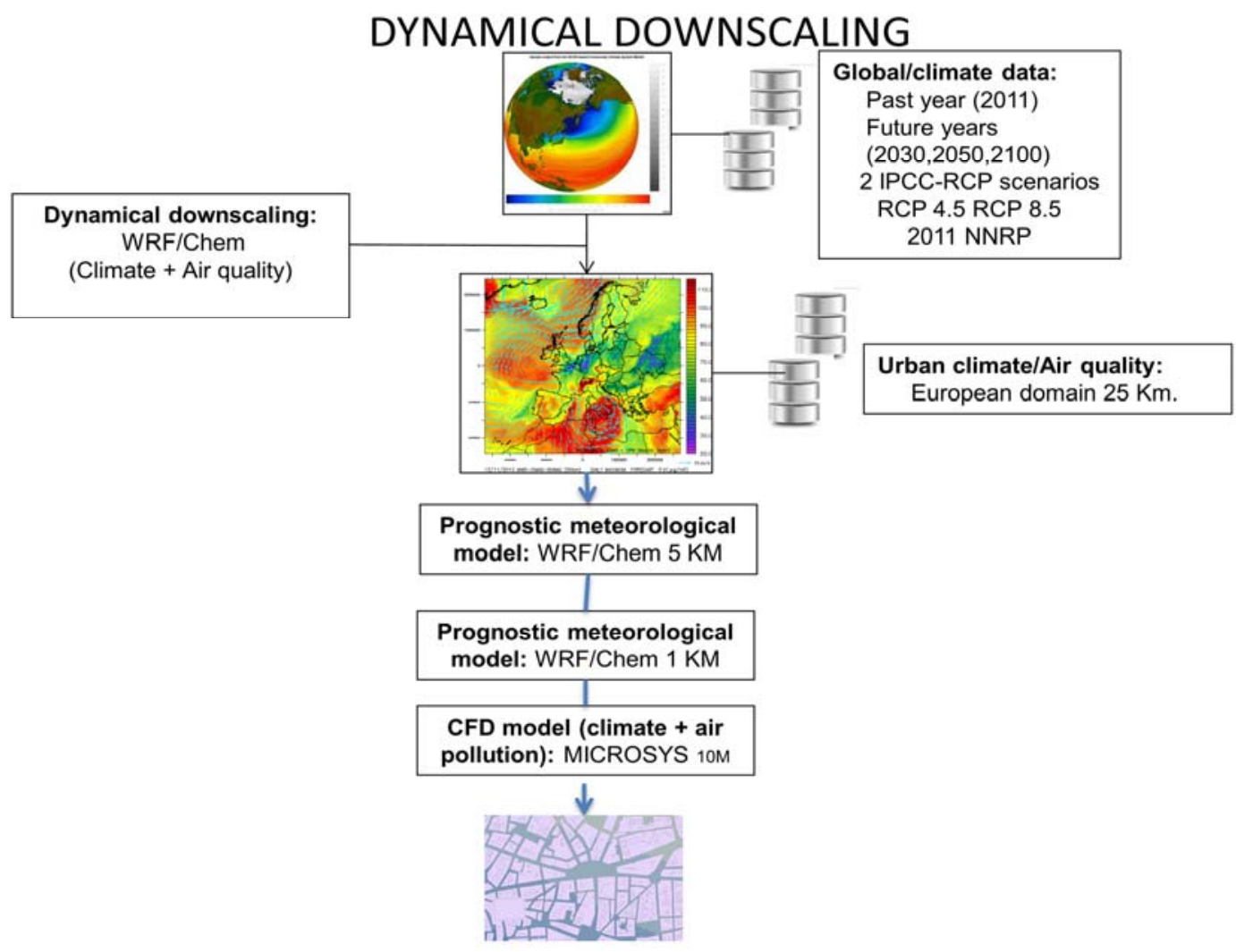

Fig. 1. Conceptual overview of the model chain used in the present study. 


\section{Results}

Spatial differences (1 km spatial resolution) of minimum temperature changes between (the large future) 2100 and 2011 (present) for RCP 4.5 and RCP 8.5 in Madrid calculated with the WRF/Chem modelling system, are showed in the Fig 2.

With the scenario 4.5 we can observe a decrease in the minimum temperature for the year 2100 up to 2.5 degrees
Celsius compared to 2011 in the north and reductions of 1.8 degrees in the center. The climate scenario 8.5 result in an increase of the minimum temperature for the year 2100 up to 1.4 degrees Celsius compared to 2011 in the downtown area. Steady state simulations of airflows over Madrid are showed in the Fig 3. It is zooming over $1 \mathrm{~km}$ by $1 \mathrm{~km}$ area to see better the wind complexity. The results come from the CFD model described above with 10 meters of spatial resolution.

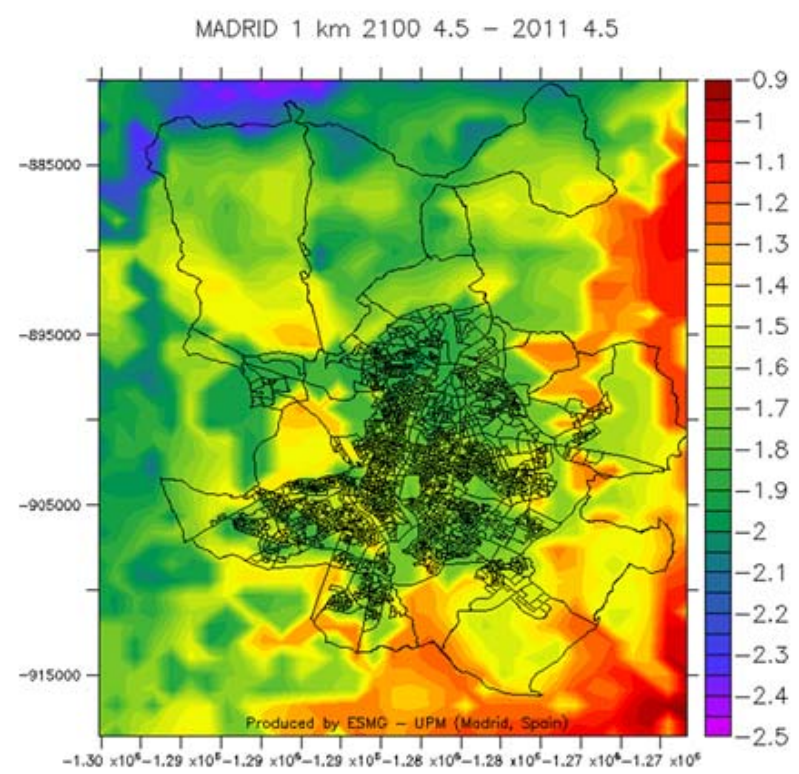

Differences of annual mean of daily minimum temperature deg $\mathrm{C}$

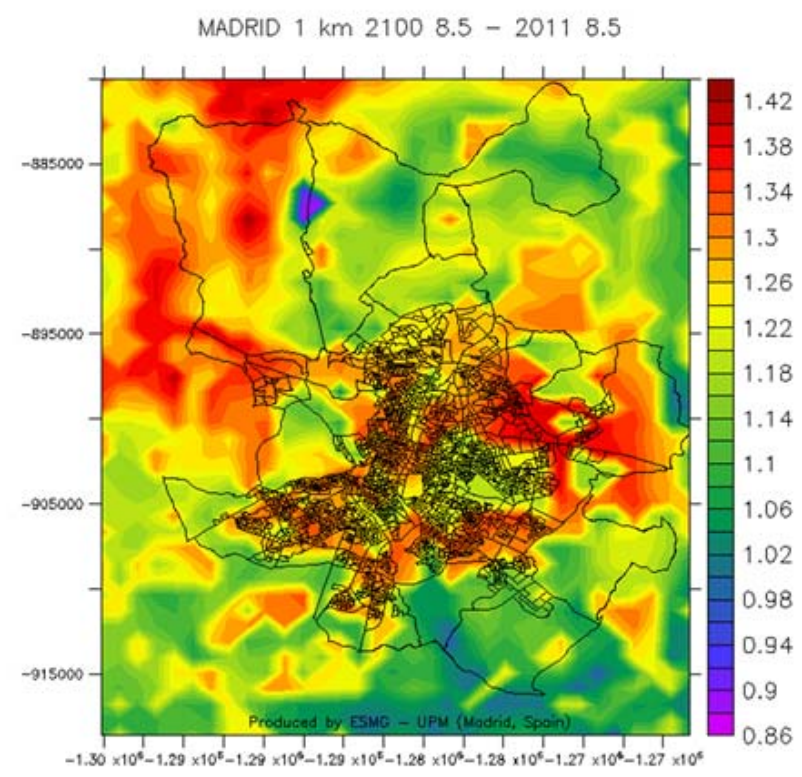

Differences of annual mean of daily minimum temperature deg $\mathrm{C}$

Fig 2:Madrid differences $\left({ }^{\circ} \mathrm{C}\right)$ between 2100 and 2011 spatial distribution (1 kilometer of resolution) of one-year average minimum air temperature with RCP 4.5 (left) and RCP 8.5 (right). Downscaled simulations using WRF-Chem.
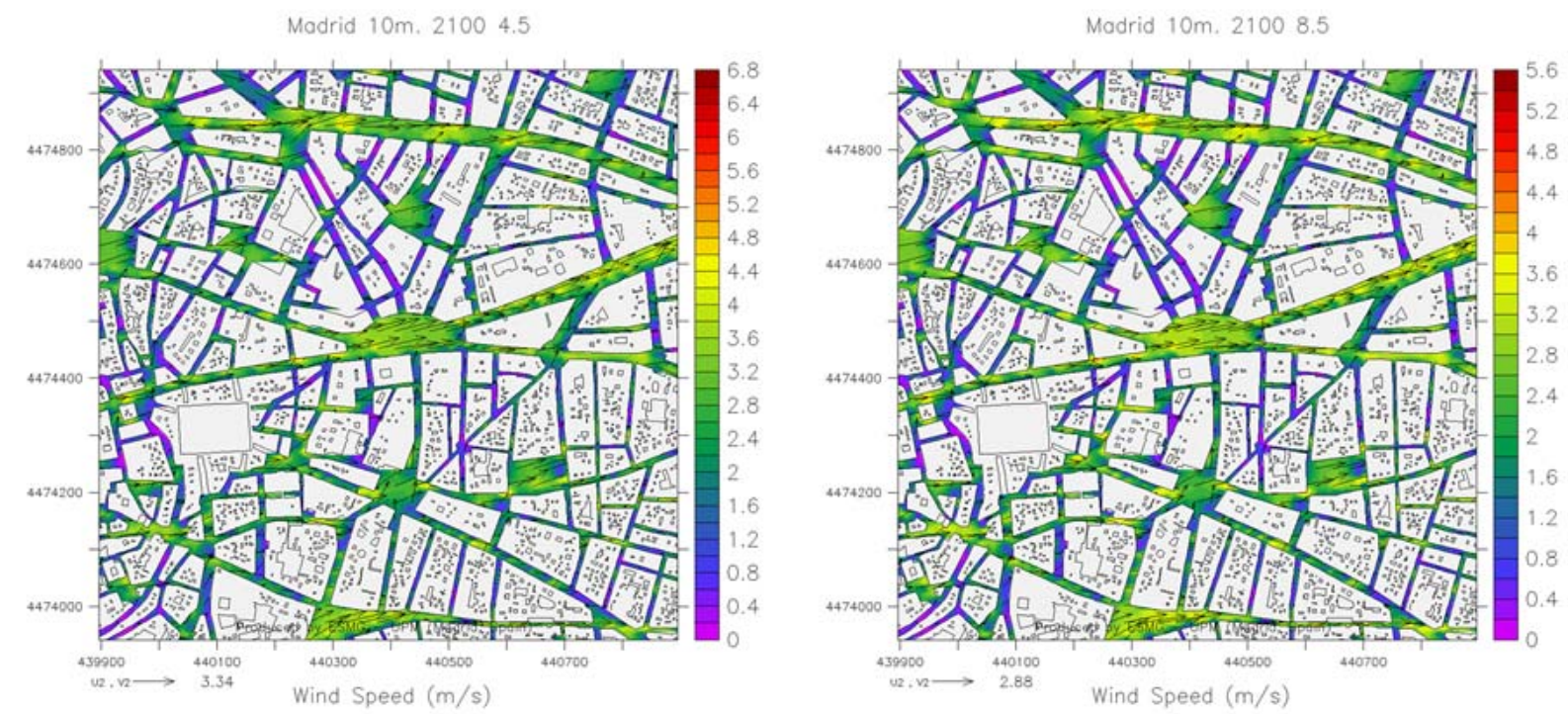

Fig 3: Zomm-in area (1 km by $1 \mathrm{~km})$ of Madrid wind vectors and wind speed (m/s) over Madrid (average winter day) for 2100 under scenario 4.5 (left) and scenario 8.5 (right). 
We have applied the EnergyPlus model to identify individually the exchange of energy between building and environment to optimize the use of energy in each building/block and to understand how the buildings in different blocks interact with the environment in terms of climate and meteorological conditions. Fig. 4 shows the monthly HVAC system energy demand for a medium office building during 2100 under two possible climate scenarios: RCP 4.5 and RCP 8.5

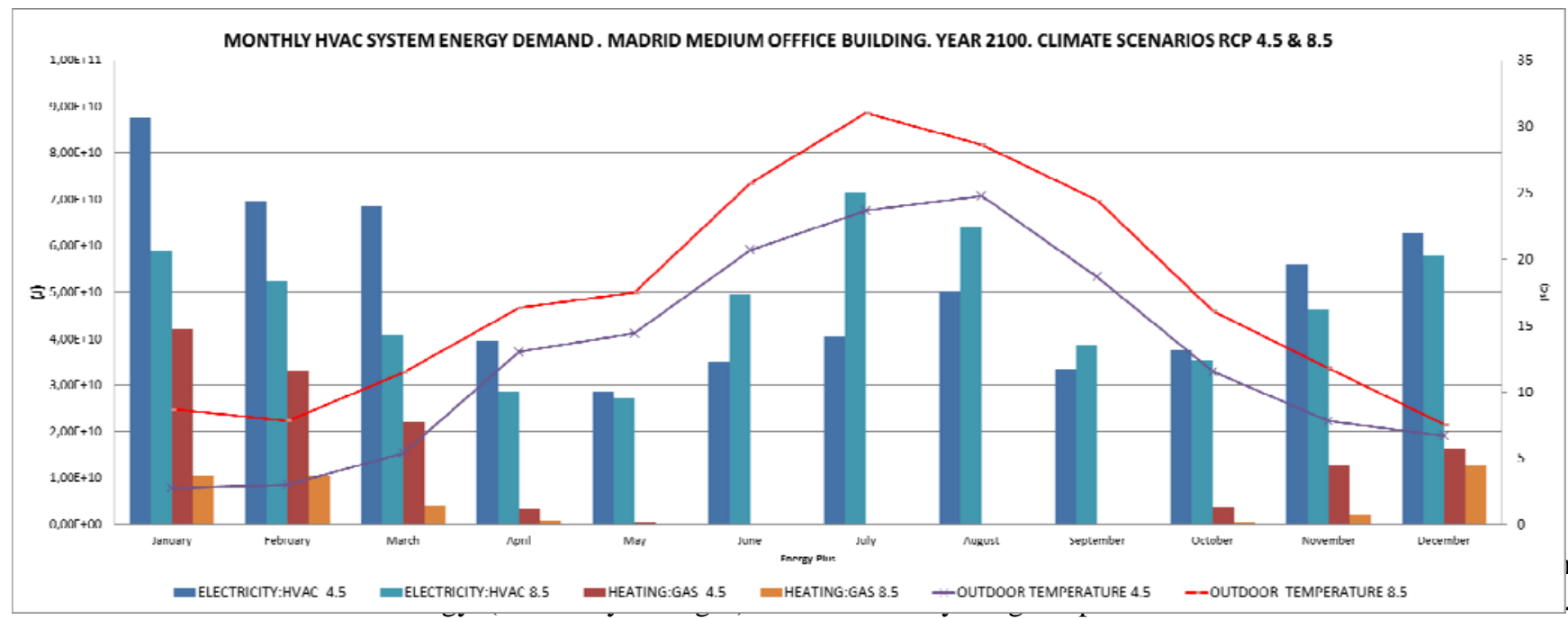

consumption will increases up to $21.3 \%$ in the climate scenario 4.5 respect to the 8.5 . If we focus on the electricity demand changes the increases are up to $6.6 \%$ and the most important changes are observed in the gas demand for heating with increases up to 222\%. Fig 4 reveals that the RCP 4.5 scenario is cooler than the RCP 8.5 based on the monthly mean of the outdoor air temperature. The demand of gas for heating in the 4.5 scenario is higher than in the 8.5, and the demand for electricity is higher in the 8.5 scenario than in the 4.5 only during the summer months. Because the outdoor temperature in the 8.5 scenario is higher than in the 4.5 , cooling energy consumption will increase (summer periods) and heating energy consumption will decrease in the 8.5 respect to the 4.5 .

\section{Conclusion}

A micro coupled simulation assessment tool was proposed and applied to study the future climate over three European cities under two IPCC RCP possible scenarios, 4.5 and 8.5. The downscaled information have been used for studying the impact of future climate projections on buildings energy demand.

In this analysis, we have isolated the effect of climate change by holding local emissions and urban morphology over time, all simulations use data from current assumptions 2011.The modelling system tool use a CFD model with boundary and initial conditions from the WRF/Chem model. The tool has been applied to examine the future urban flow in densely buil-up urban areas. Representative examples of impacts of future IPCC RPC climate scenarios 4.5 and 8.5 respect to 2011 are showed. In the high resolution simulations we have observed that the building influence is very important to detect hot spots or sensible areas to be affected by the climate change.Complex urban flows are manifest in the presence of the buildings. To improve the simulation tool, further validation studies are required by comparing simulation results with field measurements.
Building energy demand changes in response to future climate change and results are presented. The implemented system allows to know how will climate change affect building cooling and heating energy consumption. Building energy demand changes in response to future climate change, with cooling and heating demand generally going in opposite directions. These preliminary analyses conclude that the impact of climate change is generally positive for a energy demand point of view.

The impact of climate change on energy demand for heating and cooling was investigated in this study. Application of the whole building energy analysis method with medium office building models, revealed a significant relative heating energy demand decrease in the scenario 4.5 and cooling energy demand increase, over the summer period in the 8.5

Climate change not only can affect the annual heating and cooling energy consumption, it also has impacts on the peak energy use. Future works will include more detailed information about impacts, which includes different types of buildings (residential and commercial) and multiple orientations to the main sun direction.

\section{Acknowledgement}

The UPM authors acknowledge the computer resources and technical assistance provided by the Centro de Supercomputación y Visualización de Madrid (CeSViMa). The UPM authors thankfully acknowledge the computer resources, technical expertise and assistance provided by the Red Española de Supercomputación.). We acknowledge the DECUMANUS EU project from EU Space Call FP7-SPACE-2013-1 at SPA.20131.1-06. Ordnance Survey data for London: (C) Crown copyright and database rights 2015 OS 100021668. 


\section{References}

[1] Radhi, Evaluating the potential impact of global warming on the UAE residential buildings - A contribution to reduce the $\mathrm{CO} 2$ emissions. Building and Environment 44 (2009) 2451-2462.

[2] U.S. Department of Energy, Buildings Energy Data Book, Department of Energy, Washington DC, 2011.

[3] Department of Energy, EnergyPlus Engineering Reference: The Reference to EnergyPlus Calculations, Department of Energy, Washington, DC, 2010.

[4] Rao, S. \& Riahi, K. The role of non-CO2 greenhouse gases in climate change mitigation: Long-term scenarios for the 21st century. Multigas mitigation and climate policy. The Energy Journal. 3 (Special Issue), 177-200 (2006).

[5] Riahi, Steven Rose, Paul Runci, Ron Stouffer, Detlef van Vuuren, John Weyant, Tom Wilbanks, Jean Pascal van Ypersele, and Monika Zurek.. Towards New Scenarios for Analysis of Emissions, Climate Change, Impacts, and Response Strategies. Intergovernmental Panel on Climate Change, Geneva, 132 pp, (2008).

[6] Robert A., M. Kummert Designing net-zero energy buildings for the future climate, not for the past Build. Environ., 55 (2012).

[7] Rosenzweig C, Solecki W, Hammer SA, Mehrotra S. Cities lead the way in climate-change action. Nature 467: 909-911, (2010).

[8] San Jose R, Juan L. Perez, Jose L. Morant, Rosa M. Gonzalez, European operational air quality forecasting system by using MM5-CMAQ-EMIMO tool, Simulation Modelling Practice and Theory, Volume 16, Issue 10, The Analysis of Complex Systems, (2008).

[9] San Jose, R.; Perez, J. L.; Gonzalez, R. M. Urban efficient energy evaluation in high resolution urban areas by using adapted Wrf-Ucm and MICROSYS CFD models. American Geophysical Union, Fall Meeting (2009).

[10] Smith, Ronald J. Stouffer, Allison M. Thomson, John P. Weyant1 \& Thomas J. Wilbanks,. The next generation of scenarios for climate change research and assessment. Nature 463: 747-756 (2010).

[11] Westbury, P.S., Miles, S.D., Stathopoulos, T., CFD application on the evaluation of pedestrian - level winds, In Augusti G. \& Borri C. (eds), Impct of wind and storm on city life and built environment, Cost Action C14; Proc. Workshop, Nantes, (2002)

[12] Wise, MA, KV Calvin, AM Thomson, LE Clarke, B Bond-Lamberty, RD Sands, SJ Smith, AC Janetos, JA Edmonds. Implications of Limiting $\mathrm{CO} 2$ Concentrations for Land Use and Energy. Science. 324:1183-1186, (2009).

[13] Byun, J. Young, G. Gipson, J. Godowitch, F. Binkowsky, S. Roselle, B. Benjey, J. Pleim, J.K.S. Ching, J. Novak, C. Coats, T. Odman, A. Hanna, K. Alapaty, R. Mathur, J. McHenry, U. Shankar, S. Fine, A. Xiu, C. Lang, Description of the Models-3 Community Multiscale Air Quality (CMAQ) model, in: Proceedings of the American Meteorological Society 78th Annual Meeting Phoenix, AZ, January 11-16, (1998).

[14] Clarke, L., J. Edmonds, H. Jacoby, H. Pitcher, J. Reilly, R. Richels. Scenarios of Greenhouse Gas Emissions and Atmospheric Concentrations. Sub-report 2.1A of Synthesis and Assessment Product 2.1 by the U.S. Climate Change Science Program and the Subcommittee on Global Change Research. Department of Energy, Office of Biological \& Environmental Research, Washington, 7 DC., USA, 154 pp (2007).

[15] Cooney C. M., "Downscaling climate models: sharpening the focus on local-level changes," EnvironHealth Perspect, vol. 120, no. 1, pp. A24-A28, (2012).

[16] Dickinson R.E., et al. A Regional Climates Model for the Western United States Climate Change, vol. 15Kluwer Academic Publishers, Dordrecht (1989)

[17] Ehrhard, J., I. A. Khatib, C. Winkler, R. Kunz, N. Moussiopoulos, and G. Ernst,: The microscale model MIMO: Development and assessment. J. Wind Eng. Ind. Aerodyn., 85, 163-176 (2000)

[18] Grell GA, SE Peckham, R Schmitz, and SA McKeen, G Frost, WC Skamarock, and B Eder.. Fully coupled 'online' chemistry in the WRF model. Atmos. Environ., 39:6957-6976 (2005).

[19] Intergovernmental Panel on Climate Change Working group I contribution to the IPCC Fifth Assessment Report (AR5). Climate Change 2013: The Physical Science Basis (2013)

[20] Kikumoto H, et al.. Study on the future weather data considering the global and local climate change for building energy simulation Sustainable Cities Soc., 14 (2015).

[21] Gouveia Jo ao Pedro, Fortes Patrícia, Seixas Júlia. Projections of energy services demand for residential buildings: insights from a bottom-up methodology. Energy 2012;47:430e42.

[22] PNNL. 2014. Enhancements to ASHRAE Standard 90.1 Prototype Building Models. Pacific Northwest National Laboratory, Richland, Washington. Available at https://www.energycodes.gov/development/commercial/9 0.1 models. 